\title{
Role of Omicron variant of SARS-CoV-2 in children in Germany
}

\author{
Stefan Bittmann ${ }^{1}$
}

Received: 27 December 2021 / Accepted: 29 December 2021 / Published online: 1 February 2022

(c) Children's Hospital, Zhejiang University School of Medicine 2022

A new variant of SARS-CoV-2, B.1.1.529 was first reported by the South African Department of Health on Nov 24, 2021. This new variant was named as B.1.1.529 Omicron and was classified as a variant of concern (VOC) by the World Health Organization (WHO) on Nov 26, 2021 [1-13]. Phylogenetic studies showed that Omicron arose independently of the currently dominant delta variant. It has an unusually high number of approximately 30 changes of amino acids in the spike protein compared with the original SARS-CoV-2, including those with known phenotypic impact (increase in transmission, immune evasion, and transmissibility), but significances of many mutations are still unclear[4-7]. The variant has already been detected in several countries worldwide, including Germany [2, 3]. Up to Dec 8, 2021, only 15 cases of Omicron infections were determined from the Robert Koch Institute in Berlin (EU/EEA total 337 cases). On Dec 23, 2021, 3198 Omicron infections were found [1], which represents an increase of $34 \%$ in number of cases ( +810 cases) than the previous day. Concerning the age of children infected with Omicron variant, 66 were aged 0-4 years, 288 aged 5-14 years and 1501 aged $15-34$ years (till Dec 23, 2021) [1]. Reinfections with Omicron were found in two patients (5-14 years old age group) [1]. No children infected with the Omicron variant were fatal till Dec 23, 2021 [1].

So far, the Omicron variant is not known to be more contagious. The number of infected persons and thus also of children will increase dramatically. However, it is not yet clear whether Omicron also leads more frequently to severe courses of disease [1-13]. If Omicron makes people less ill, it is possible that more children will be hospitalized than is the case now simply because of the high number of infected cases. The statement by Health Minister Karl Lauterbach of Germany that "the Omicron variant is particularly dangerous

Stefan Bittmann

stefanbittmann@gmx.de

1 Department of Pediatrics, Medical and Finance Center Epe, Ped Mind Institute (PMI), Hindenburgring 4, 48599 Gronau, Germany for children and would lead to high hospitalization rates" is obviously not supported by facts. Lauterbach is apparently referring to a study from South Africa and its reception in Indian media. According to the virologist Klaus Stöhr, with whom the Berliner Zeitung spoke on the subject, the study was pre-published on Dec. 5 and then excerpts were also presented at a meeting of the World Health Organization (WHO) on Dec. 7. WHO announced that Omicron is spreading, but the number of severe cases in South Africa remains low. The very limited data from the study would suggest that the course of the disease may well be milder. This is concluded because very many patients, including many children and adolescents, tested positive for corona only at the hospital on admission but were actually admitted for other reasons. The New York Times reported that the proportion of asymptomatic and mild disease was, therefore, apparently much higher than that in previous waves, according to the initial observations. The portrayal that children were being affected by Omicron misses the data. The Indian media are also very cautious about drawing conclusions. The current data worldwide do not yet say anything reliable about the dangerousness of the variant or the degree of hospitalization. The medical treatment seems not extraordinary different from Covid-19. Oxygen, interleukin-6 inhibitors, JAK inhibitors and other therapies should also play an important role as treatment options.

Omicron is a new viral variant with an unpredictable outcome. Time will show further severity in the pediatric population.

Author contributions Stefan Bittmann is the only author.

Funding None.

\section{Declarations}

Ethical approval Not required for this editorial.

Conflict of interest None. 


\section{References}

1. tägliche Übersicht von Omicronfällen. www.rki.de. Accessed 23 Dec 2021.

2. Lima DGS, Figueiredo TMR, Pereira YTG, Almino MAFB, Pereira LM, de Menezes HL, et al. The effects of the silence on south African children and adolescents against a global alert on the newly identified coronavirus variant: Omicron. J Pediatr Nurs. 2021;S0882-5963:365-71. https://doi.org/10.1016/j.pedn.2021. 11.032 .

3. Vaughan A. Omicron emerges. New Sci. 2021;252:7.

4. Russell RS. Omicron: a speculation on its potential superpowers. Viral Immunol. 2021;34:664-5.

5. Kupferschmidt K. Where did "weird" Omicron come from? Science. 2021;374:1179.

6. National Center for Immunization and Respiratory Diseases (NCIRD), Division of Viral Diseases. CDC COVID-19 Science Briefs [Internet]. Atlanta (GA): Centers for Disease Control and Prevention (US); 2020. Science Brief: Omicron (B.1.1.529) Variant. https://www.cdc.gov/coronavirus/2019-ncov/science/sciencebriefs. Accessed 2 Dec 2021.
7. Ferré VM, Peiffer-Smadja N, Visseaux B, Descamps D, Ghosn J, Charpentier C. Omicron SARS-CoV-2 variant: What we know and what we don't. Anaesth Crit Care Pain Med. 2021;41:100998.

8. Thakur V, Kanta RR. OMICRON (B.1.1.529): a new SARSCoV-2 Variant of Concern mounting worldwide fear. J Med Virol. 2021. https://doi.org/10.1002/jmv.27541.

9. Fang FF, Shi PY. Omicron: a drug developer's perspective. Emerg Microbes Infect. 2021. https://doi.org/10.1080/22221751.2021. 2023330.

10. Ledford H. How severe are Omicron infections? Nature. 2021;600:577-8.

11. Cohen J. Omicron sparks a vaccine strategy debate. Science. 2021;374:1544-5. https://doi.org/10.1126/science.acz9879.

12. Rubin EJ, Baden LR, Abdool Karim SS, Morrissey S. Audio interview: the Omicron variant of SARS-CoV-2. N Engl J Med. 2021;385:e96. https://doi.org/10.1056/NEJMe2118839.

13. Mahase E. Covid-19: Omicron and the need for boosters. BMJ. 2021;375: n3079. https://doi.org/10.1136/bmj.n3079.

Publisher's Note Springer Nature remains neutral with regard to jurisdictional claims in published maps and institutional affiliations. 